\title{
High-definition mapping of the atria using a novel multipolar mapping catheter in patients with complex adult congenital heart disease
}

\author{
Mohammad Paymard and Santabhanu Chakrabarti
}

\begin{abstract}
Background: The Advisor ${ }^{\mathrm{TM}}$ HD Grid Mapping Catheter (Abbott Technologies, Minneapolis, MN) has been recently introduced. Although the clinical use of HD Grid mapping catheter is well described in adults with no congenital heart disease, there is limited data on the feasibility of using the HD Grid multipolar catheter to create voltage and activation mapping in adults with congenital heart disease. The purpose of this study was to evaluate the safety and technical feasibility of using the Advisor ${ }^{\mathrm{TM}} \mathrm{HD}$ Grid mapping catheter during the catheter ablation of atrial arrhythmias in adults with congenital heart disease. We included 6 consecutive adults with congenital heart disease suffering from atrial arrhythmias in our study. The HD Grid mapping catheter was used to perform voltage and activation mapping.

Results: Six patients with congenital heart diseases (d-TGA $n=1$, Tricuspid atresia $n=1$, atrioventricular defect repair $n=1$, secundum atrial septal defect $n=1$, double-inlet single-ventricle $n=1$, Tetralogy of Fallot $=1$ ); majority (84\%) male, with the mean age was $35 \pm 10$ years included in our series. The mean ablation duration and the fluoroscopy time were $789 \pm 433$ and $502 \pm 355$ s, respectively. The mean radiation dose was $7.52 \pm 9$ milliGy/ $\mathrm{cm}^{2}$. The HD Grid mapping catheter was used successfully for entire arrhythmia mapping in 5 out of 6 cases. During one procedure, HD Grid mapping catheter could not be used for the entire mapping due to suboptimal reach through baffle puncture. The acute success rate of ablation was $100 \%$ with no immediate complications.

Conclusions: The use of HD Grid mapping catheter is a safe and valuable adjunct to accurately create voltage and activation mapping in ACHD patients undergoing radiofrequency catheter ablation. However, a contact force-sensing ablation catheter should be considered in conjunction to supplement data acquisition in challenging anatomy and substrates.
\end{abstract}

Keywords: Adult congenital heart disease, HD Grid mapping catheter, Supraventricular tachycardia, Atrial tachyarrhythmia, Atrial flutter

\section{Background}

Adults with complex congenital heart disease (ACHD) may develop symptomatic drug-refractory arrhythmias requiring electrophysiology (EP) studies and catheter ablations. The arrhythmia substrates include scars from

*Correspondence: schakrabarti@providencehealth.bc.ca Centre for Cardiac Innovation, Division of Cardiology, Department of Medicine, University of British Columbia, 1033 Davie St Suite 211, Vancouver, BC V6E 1M7, Canada previous cardiac surgeries, abnormal cardiac anatomy and changes in electrophysiological properties of the myocardium due to chronic myocardial remodelling [1, 2]. The dominant mechanism of atrial arrhythmias (AA) in ACHD population is intra-atrial-re-entrant tachycardia (IART) which manifest as macro-reentry atrial tachycardia (MAT), atrial flutter (AFL) and focal atrial tachycardia [3]. Catheter ablation of AAs in ACHD patients is generally challenging considering the modified cardiac anatomy and extensive tachycardia substrates. original author(s) and the source, provide a link to the Creative Commons licence, and indicate if changes were made. The images or other third party material in this article are included in the article's Creative Commons licence, unless indicated otherwise in a credit line to the material. If material is not included in the article's Creative Commons licence and your intended use is not permitted by statutory regulation or exceeds the permitted use, you will need to obtain permission directly from the copyright holder. To view a copy of this licence, visit http://creativecommons.org/licenses/by/4.0/. 
Conventional ablation involves local bipolar and unipolar electrograms (EGM) including the amplitude and morphology to identify ablation targets, but their inherent drawbacks limit their accuracy, especially in complex ACHD substrates [4].

Studies have demonstrated that the use of threedimensional electroanatomic mapping systems to guide atrial arrhythmia ablation in ACHD patients are associated with better clinical outcome [5, 6]. Traditionally, either the ablation catheter or a circumferential mapping catheter is utilized to create the geometry of the chamber of interest and to perform the activation mapping. Owing to their complex cardiac anatomy, the mapping process is often time-consuming and challenging in ACHD patients. Often, these patients have multiple inducible arrhythmias, so repeated mapping is time-consuming and also makes the procedure long.

Recently, the Advisor ${ }^{\mathrm{TM}}$ HD Grid Mapping Catheter (Abbott Technologies, Minneapolis, MN) has been introduced. This catheter is uniquely designed in a steerable bidirectional platform with a grid consisting of 16 equidistant electrodes across 4 splines with 3-3.3 mm spacing allowing precise electrogram acquisition. One study reported that the HD Grid mapping catheter (HGMC) could facilitate rapid and accurate high resolution atrial mapping for catheter ablation of atrial tachycardia and atrial fibrillation in non-ACHD patients [7].

HGMC theoretically would be a very well-suited diagnostic catheter for ACHD cases, but the data concerning the role of HGMC to guide catheter ablation in ACHD population with abnormal anatomy is not available. The purpose of our study was to assess the feasibility and safety of using the HGMC to facilitate the catheter ablation in patients with ACHD.

\section{Methods}

This case series includes six consecutive ACHD patients referred to our centre for EP study and catheter ablation of drug refractory symptomatic AAs. They underwent pre-procedural cardiac computed tomography to delineate substrate anatomy. All antiarrhythmic drugs were discontinued at least five half-lives prior to the procedure.

\section{EP study and ablation}

AAs were induced using the programmed atrial stimulation protocol unless the patient was already in AA on arrival at the EP laboratory. Ensite Precision cardiac three-dimensional mapping system (St. Jude Medical, St. Paul, Minnesota), HGMC and TactiCath ${ }^{\text {TM }}$ Contact Force Ablation Catheter was used for or all cases. The geometry of the chamber(s) of interest was created initially with a force sensing catheter (TactiCath) to delineate appropriate shell (contact force 5-10 gm) to ensure optimal endocardial contact with HGMC followed by deployment of the HGMC. A decapolar catheter was placed in the coronary sinus or superior vena cava as a reference point for geometry creation and arrhythmia activation mapping.

\section{Results}

\section{Baseline characteristics}

Six ACHD patients were included in the study. Five (84\%) were male with mean age $35 \pm 10$ years. The mean ablation duration and the fluoroscopy time were $789 \pm 433$ and $502 \pm 355 \mathrm{~s}$, respectively. The mean radiation dose was $7.52 \pm 9 \mathrm{mGy} / \mathrm{cm}^{2}$ (Additional clinical details are available in Table 1). The mean total collected points during the activation mapping of IARTs and the mean activation mapping time were $5413 \pm 2376$ and $11 \pm 8 \mathrm{~min}$, respectively (Table 2).

Table 1 Clinical and electrophysiological characteristics of patients

\begin{tabular}{|c|c|c|c|c|c|c|c|c|}
\hline $\begin{array}{l}\text { Patient } \\
\text { number }\end{array}$ & Age (Y) & Gender & $\begin{array}{l}\text { Type of congenital } \\
\text { heart disease }\end{array}$ & Type of tachycardia & Procedure performed & $\begin{array}{l}\text { Ablation } \\
\text { duration } \\
\text { (Second) }\end{array}$ & $\begin{array}{l}\text { Fluoroscopy } \\
\text { time (Second) }\end{array}$ & $\begin{array}{l}\text { Radiation } \\
\text { dose (Gy/ } \\
\left.\mathrm{cm}^{2}\right)\end{array}$ \\
\hline$\# 1$ & 32 & Female & d-TGA & IART & $\begin{array}{l}\text { Critical Isthmus abla- } \\
\text { tion }\end{array}$ & 402 & 1008 & 3.35 \\
\hline$\# 2$ & 38 & Male & Tricuspid atresia & IART & Substrate modification & 1218 & 444 & 4.55 \\
\hline \#3 & 50 & Male & Tetralogy of Fallot & IART & Substrate modification & 774 & 672 & 23.5 \\
\hline$\# 4$ & 23 & Male & $\begin{array}{l}\text { Atrioventricular septal } \\
\text { defect }\end{array}$ & IART & $\begin{array}{l}\text { Critical Isthmus abla- } \\
\text { tion }\end{array}$ & 320 & 78 & 1.07 \\
\hline \#5 & 76 & Male & $\begin{array}{l}\text { secundum atrial septal } \\
\text { defect }\end{array}$ & Atrial fibrillation & $\begin{array}{l}\text { Pulmonary veins } \\
\text { isolation }\end{array}$ & 4935 & 354 & 3.76 \\
\hline \#6 & 35 & Male & $\begin{array}{l}\text { Double-inlet single- } \\
\text { ventricle heart and } \\
\text { TGA }\end{array}$ & IART & $\begin{array}{l}\text { Critical Isthmus abla- } \\
\text { tion }\end{array}$ & 1233 & 312 & 5.13 \\
\hline
\end{tabular}


Table 2 IART activation map and substrate map characteristics

\begin{tabular}{|c|c|c|c|c|}
\hline Patient \# & Type of map & $\begin{array}{l}\text { Total points collected during } \\
\text { mapping }\end{array}$ & Map point used & Time to map \\
\hline 1 & IART activation map & 8108 & 1495 & $6 \min 8 s$ \\
\hline 2 & Substrate map & 3186 & 1518 & $32 \min 26 s$ \\
\hline 3 & Substrate map/IART activation map & 8597 & 2350 & $35 \min 24 \mathrm{~s}$ \\
\hline 4 & IART activation map & 4512 & 1075 & $7 \min 7$ \\
\hline 5 & Substrate map (pre and post PVI) & 6115 & 1592 & $17 \min 11 \mathrm{~s}$ \\
\hline 6 & IART activation map & 3619 & 1394 & $21 \min 22 \mathrm{~s}$ \\
\hline
\end{tabular}

IART intra-atrial re-entrant tachycardia, $P V I$ pulmonary vein isolation

\section{Patient \#1}

In this patient with atrial baffle, the presenting rhythm during the procedure was atypical AFL with the cycle length (CL) of 296 (ms). The Mustard baffle was punctured with transesophageal echocardiography guidance. Use of HGMC was easy in the superior vena cava (SVC) and inferior vena cava (IVC) baffles and the systemic venous atrium. However, HGMC was unable to reach the inferior aspect of the pulmonary venous atrium, due to the position of the baffle puncture, with resultant incomplete data acquisition. The TactiCath was used to supplement activation mapping data. The tachycardia was propagating around the right-sided atrioventricular valve (AV) annulus in a counter-clockwise fashion (Fig. 1). The right-sided AV valve to IVC isthmus region was successfully ablated anterior and posterior to the baffle and bidirectional electrical conduction block was achieved. There was no inducible AA post procedure.

\section{Patient \#2}

In this patient with univentricular physiology, we were unable to induce any tachycardia in the EP laboratory. After initial Fontan geometry creation with TactiCath (5-10 gm force), voltage and activation map during sinus rhythm was performed with HGMC, revealing two potential isthmus areas with critically slow conduction; one located posterosuperiorly between right atrial wall scar and the superior vena cava and the second area was between the right side of atrioventricular groove and

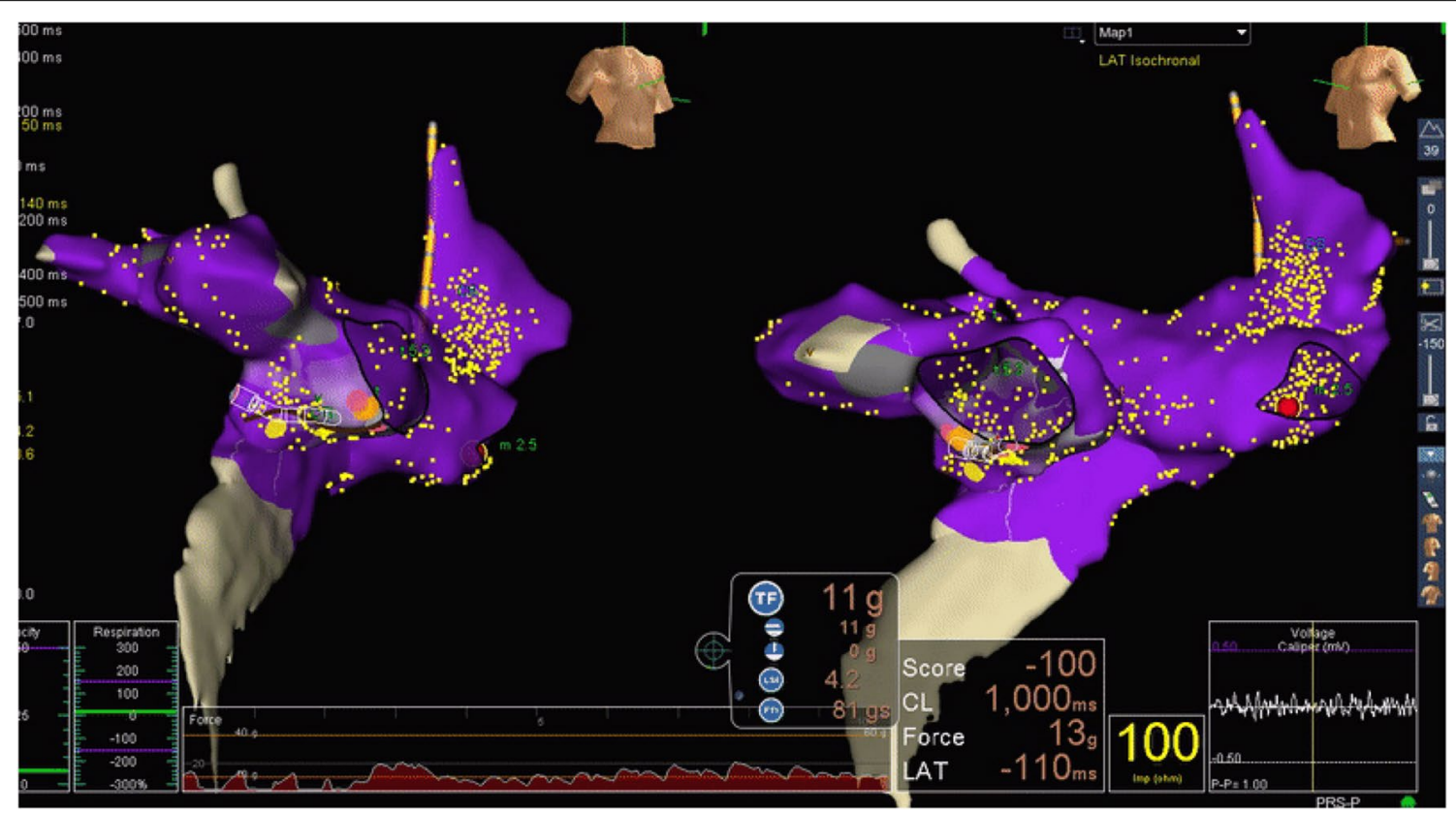

Fig. 1 The right anterior oblique view-the left image- and the left anterior oblique view -the right image- are demonstrating the macrorentry AA that is propagating around the right-sided atrioventricular valve annulus (morphologic tricuspid valve) in a counter-clockwise fashion. The patient had history of D-transposition of great arteries status post Mustard procedure and superior vena cava stenosis requiring stenting 
the inferior vena cava (Fig. 2). These isthmus areas were ablated. There was no inducible AA post procedure.

\section{Patient \#3}

This patient with repaired Tetralogy of Fallot had a very dilated right atrium (RA). The RA geometry was initially created using the ablation catheter (TactiCath). HGMC guided voltage mapping identified an area of scar in the posterior inferior RA (Fig. 3). An IART with CL of $380 \mathrm{~ms}$ was induced following a programmed atrial stimulation which was mapped with HGMC. After initial ablation, HGMC also identified an area on the posterior aspect of the RA which was giving rise to a significant amount of premature atrial complexes. The critical isthmus area and
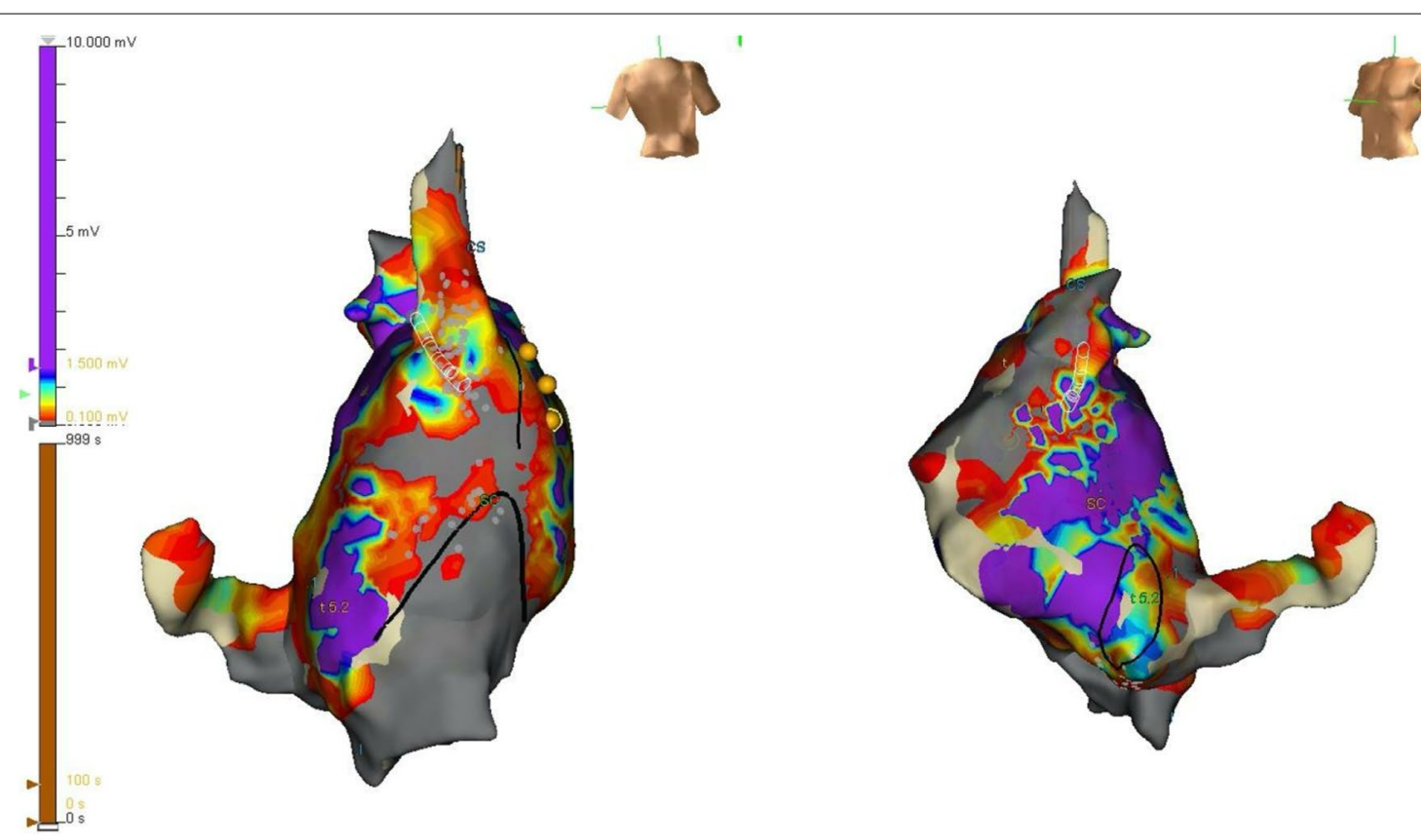

Fig. 2 The voltage mapping of the atrium revealed two areas with critically slow conduction. One located posterosuperiorly between right atrial wall scar and the superior vena cava and the second area was between the right side of atrioventricular groove and the inferior vena cava. The patient had history of tricuspid atresia, pulmonary stenosis, bilateral modified Blalock Shunt and Fontan Procedure
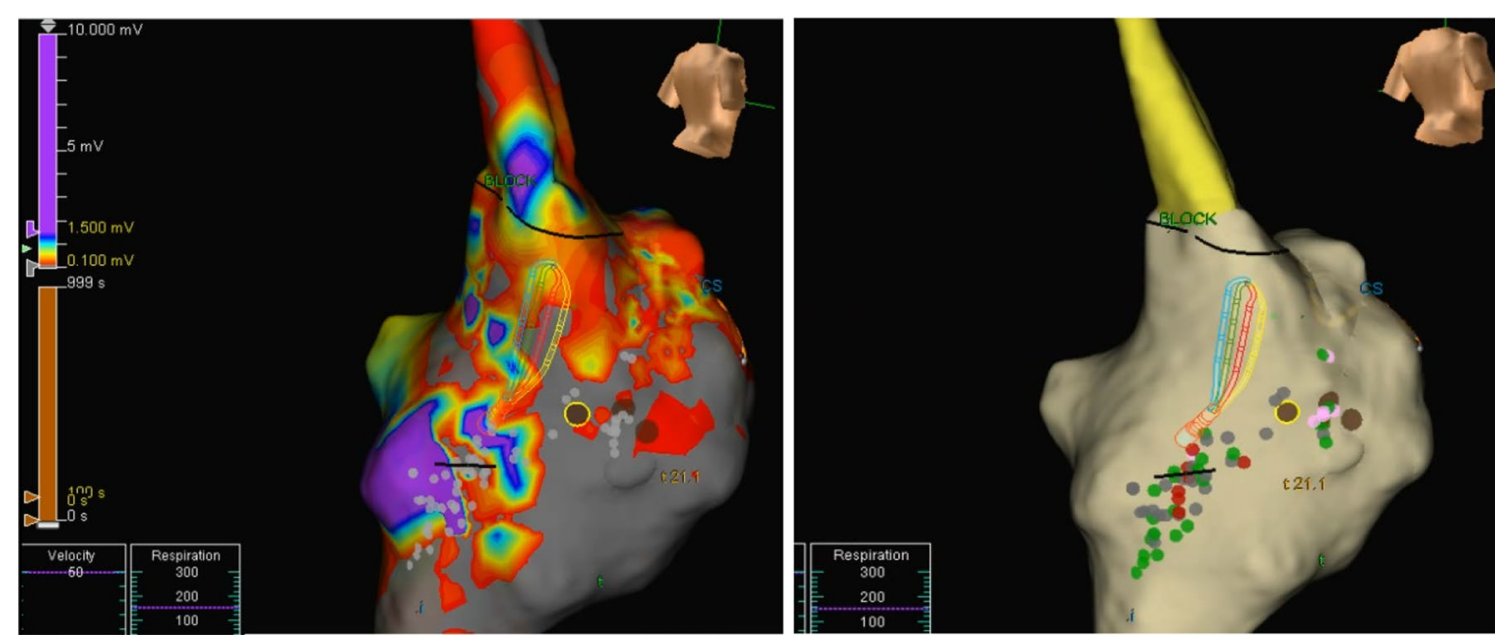

Fig. 3 The voltage mapping of the right atrium identified the tachycardia substrate in posterior inferior lateral wall of the right atrium which was successfully ablated. The patient had history of Tetralogy of Fallot required several surgical repairs 
the premature atrial complex focus were ablated successfully. The tachycardia was non-inducible post ablation.

\section{Patient \#4}

This patient with repaired atrioventricular septal defect presented with an IART with the CL $244 \mathrm{~ms}$ in the EP laboratory. After creating the initial endocardial shell of the RA with TactiCath, the voltage and activation mapping of the IART were performed using the HGMC. The activation map was suggestive of a right AV valve to IVC isthmus-dependent clockwise flutter (Fig. 4). The isthmus region then was successfully ablated and bidirectional block was achieved. No arrhythmia was inducible post ablation.

\section{Patient \#5}

This 76-year-old patient with large unrepaired atrial septal defect with pulmonary hypertension and decompensated heart failure underwent bilateral pulmonary vein isolation (PVI) procedure for drug refractory persistent atrial fibrillation. After creating initial endocardial shell with TactiCath, the HGMC was used to perform left atrial geometry and voltage mapping. Following PVI, the left atrial voltage mapping was repeated. This revealed acute reconnection of left superior pulmonary vein and right inferior pulmonary vein PV requiring re-ablation which was successfully performed (Fig. 5).

\section{Patient \#6}

In this 35-year-old patient with Fontan circulation, the initial endocardial geometry of the classical Fontan shell was created with the TactiCath, the HGMC was used to create the RA and Fontan circuit geometry. Following programmed atrial stimulation, a IART with CL of $300 \mathrm{~ms}$ was induced. The activation mapping showed that AFL was using the isthmus between the right-sided AV valve and the IVC and a part of the Fontan circuit (Fig. 6). The isthmus area was successfully ablated, bidirectional block was achieved and the tachycardia was non-inducible post procedure.

\section{Complications}

There was no acute procedure-related or HGMC use related-complications.

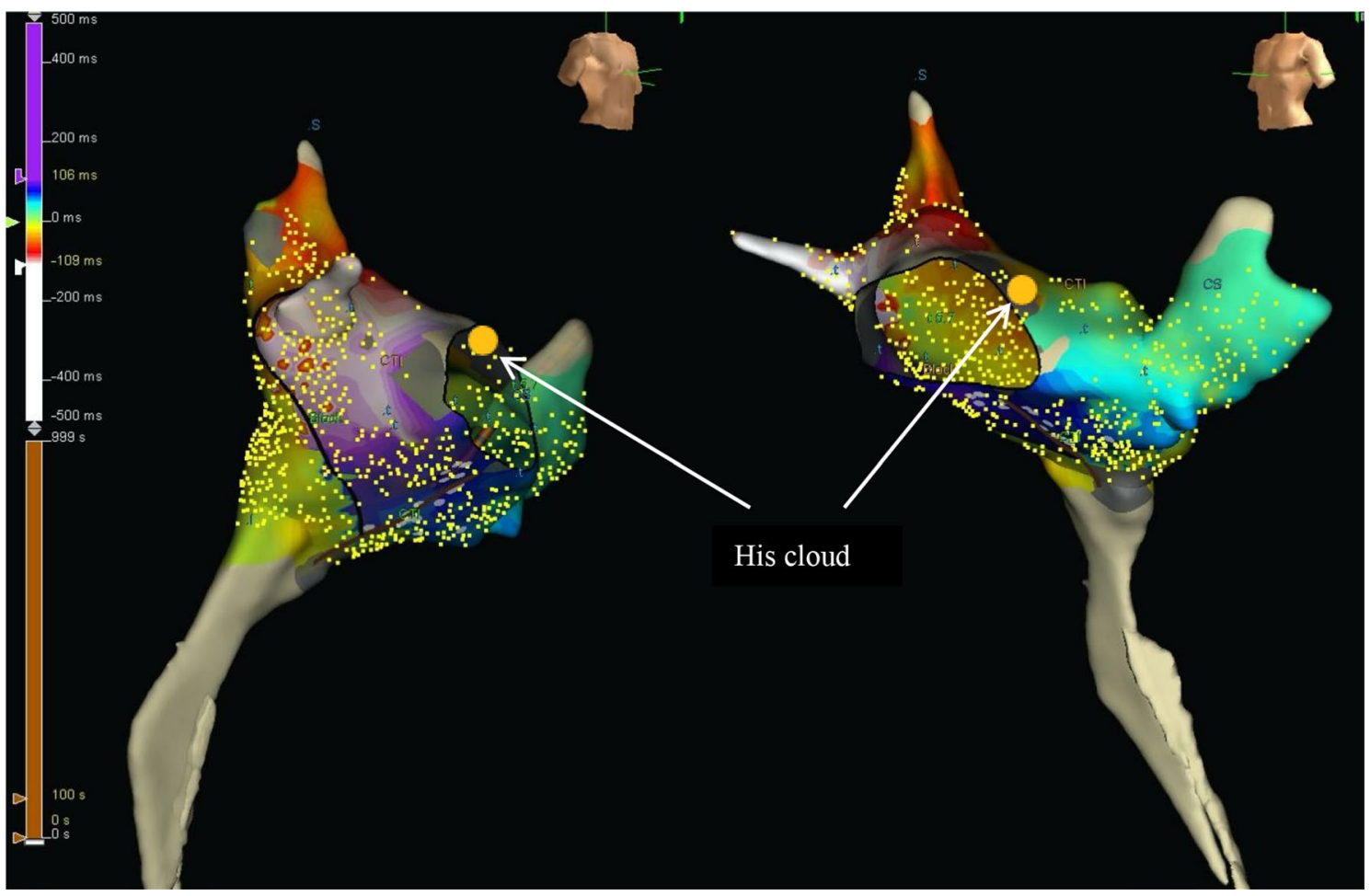

Fig. 4 The right anterior oblique (left image) and left anterior oblique views (right image) of the activation map were consistent with CTI-dependent clockwise right atrial flutter. The His Cloud (white arrows) was $16 \mathrm{~mm}$ away from the ablation site. The patient had history of atrioventricular septal defect required surgical repair as well as persistent left sided superior vena cava 


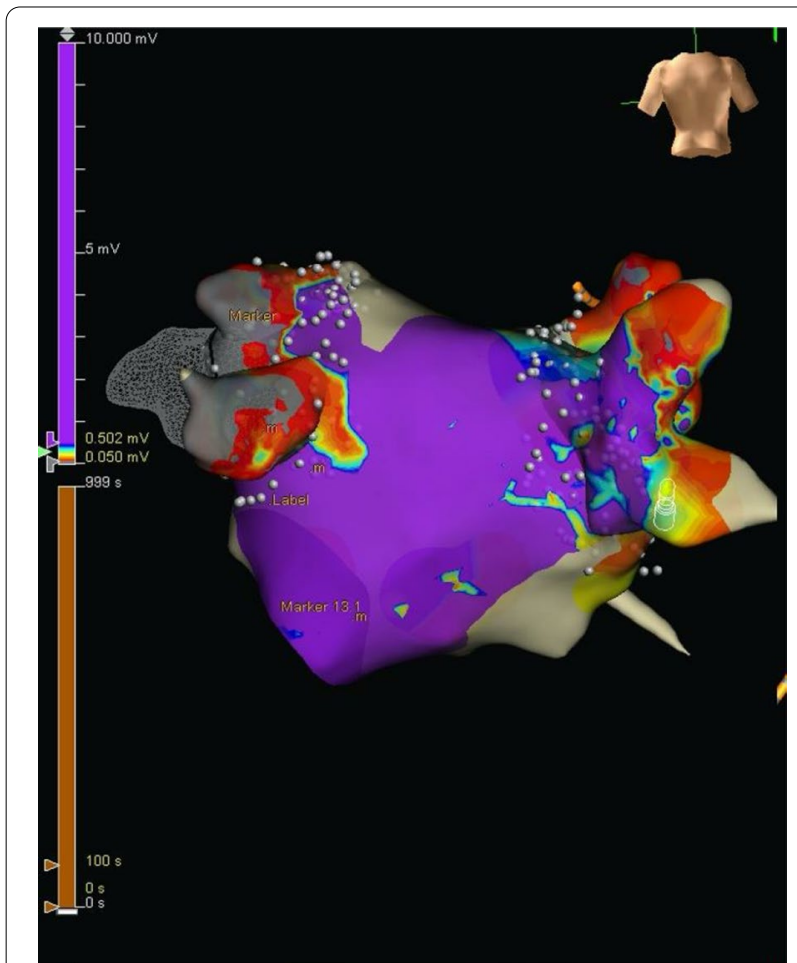

Fig. 5 Post PVI voltage mapping revealed acute reconnection of left superior pulmonary vein and right inferior pulmonary vein. The patient had history of secundum atrial septal defect

\section{Follow-up}

All patients have remained asymptomatic and with no evidence of the recurrence of original arrhythmias on ECG or Holter monitor during 6-month follow-up.

\section{Discussion}

This study demonstrated that HGMC is a useful adjunct to perform high density activation and substrate mapping in complex atrial ablations in a series of ACHD patients and result in relatively short mapping and procedural times with excellent immediate and short term success.

The unique configuration of the HGMC includes a paddle consisting of $4 \times 4$ grid of 16 equidistant electrodes across 4 splines with 3-3.3 mm spacing (Fig. 7). These specifications allow fast and accurate high-density bi-dimensional bipolar recording along and across the splines required for substrate and activation mapping.

Unlike traditional mapping catheters which only record bipolar signals in one direction, HGMC has the ability of performing uninipolar mapping that allows greater mapping sensitivity regardless of wavefronts' direction of activation. The ability of HGMC to simultaneously record bipolar EGMs along and across the splines (orthogonal bipolar EGMs) at the same location enables the mapping system to choose the best EGM with the highest peakto-peak voltage to create high-definition map (HD wave solution) [8].

The bidirectionality of HGMC enables the catheter to reach up to $35 \mathrm{~mm}$ in D curve and up to $42 \mathrm{~mm}$ in

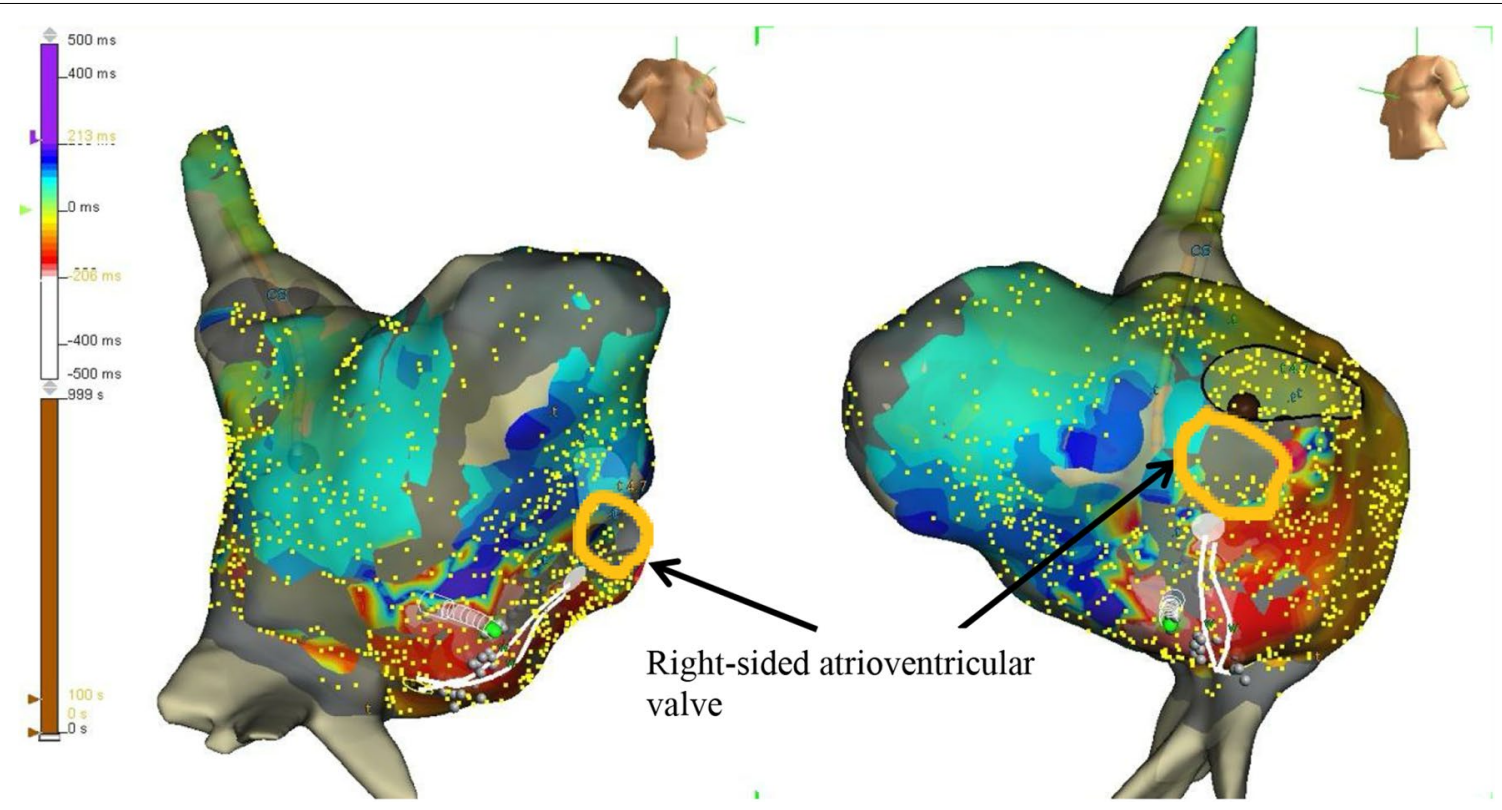

Fig. 6 The activation mapping of showed that AFL was using the isthmus between the right-sided atrioventricular valve and the inferior vena cava and a part of the Fontan circuit The patient had history of double-inlet single-ventricle heart with transposition of great arteries required several surgical repairs including Blalock shunt and classic Fontan procedure connecting right atrium to pulmonary artery. 


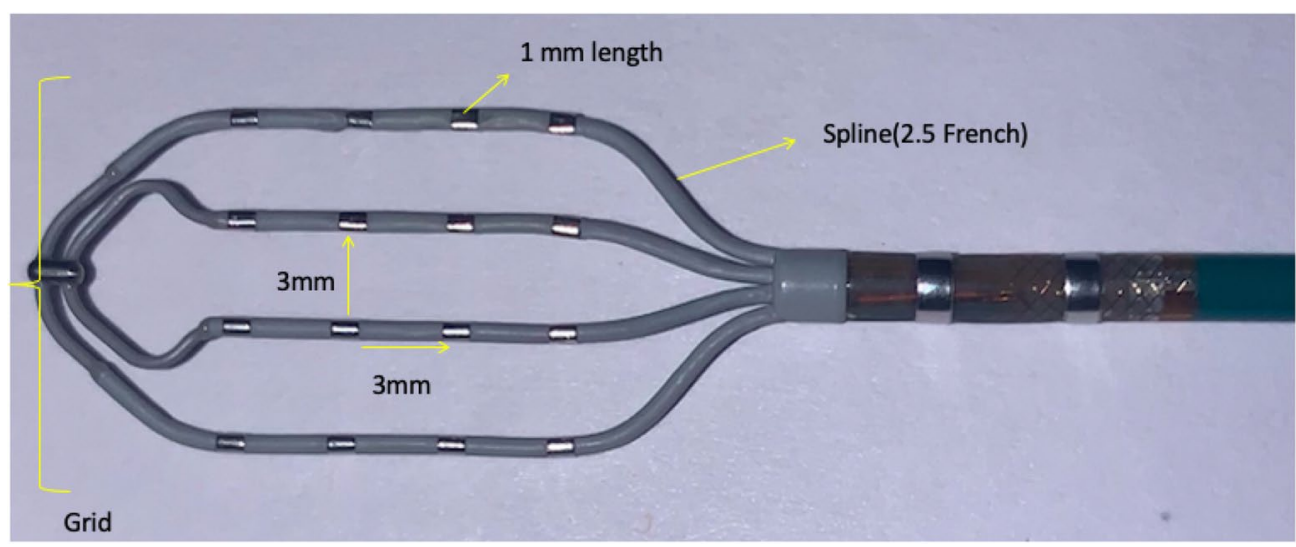

Fig. 7 The Advisor ${ }^{\mathrm{TM}}$ HD Grid catheter is a bidirectionally steerable mapping catheter that has four splines consisting of 4 electrodes each. Inter-electrode spacing is $3 \mathrm{~mm}$ equally across and along the splines

F curve flexion which makes it very useful to reach the target of interest in very large chambers of interest, especially very dilated cardiac chambers like atrio-pulmonary Fontan circuits.

We did not notice any discernible arrhythmogenicity of HDMC, presumably due to the flexibility. However, we had to be cautious with its manoeuvrability in relatively stiffer cardiac anatomy like intracardiac baffles and near calcified areas and prosthetic valves. Also, the catheter needs to be negotiated carefully in smaller structures as coronary sinus and smaller pulmonary veins.

Hong et al. demonstrated that in non-ACHD population undergoing PVI, the HGMC could rapidly and accurately assess bidirectional conduction block along the line of ablation as well as identifying areas of acute reconnection [7]. In our ACHD patient with AF who underwent PVI, the HGMC similarly was able to quickly identify the points of acute reconnection.

In our experience of using HGMC for ACHD cases with IARTs and AF was safe and valuable. The catheter was able to rapidly and accurately collect electrogram data samples in order to create substrate and activation mapping in these anatomically complex patients. The HGMC was able to collect very high number of points to create the maps in relatively short period of time in patients with complex cardiac anatomy. These advantages of the HGMC could potentially reduce ablation time, fluoroscopy time and radiation dose.

This important observation needs to be validated in a larger study where the performance HGMC and conventional mapping catheters could be compared in ACHD population. Due to the close inter-electrode spacing, another capability of HGMC was, recognizing the tachycardia substrate(case\#2\&3), especially in the presence of a scar.
One of the disadvantages of using HGMC that we encountered was the HGMC's limited manoeuvrability in small or non-distensible cavities (e.g. atrial baffles in Mustard circuit)and potential of generating relatively high wall tension if used for shell geometry creation as the primary tool as the tactile feedback of the HGMC itself is unreliable.

In certain areas of ACHD anatomy and in several paediatric patients, HGMC may be too large and therefore difficult to manoeuvre, so supplemental data acquisition with a smaller catheter is required. We therefore propose the manufacturer could also consider producing HGMC with a smaller grid and spines that would be suitable to use in smaller structures like the coronary sinus, pulmonary veins, perivalvar substrates, etc., not only for ACHD patients but also the paediatric population.

\section{Study limitation}

The present study was a small case series that has its own limitations. However, we were able to demonstrate that using HGMC in ACHD patients with AA is feasible and safe. There are significant anatomical and substrate variabilities in ACHD population which limit the scope of larger studies.

\section{Conclusions}

The HGMC identifies areas of potential electrical isthmuses and reconduction in complex ACHD atrial arrhythmias. The rapid data acquisition of the HGMC facilitates fast detection and analysis of arrhythmias and results in potentially low procedure times and radiation exposure for the patient and the health care providers. The role of HGMC may be limited in some ACHD anatomies, but when used judiciously and in conjunction with other catheters, the HGMC use is feasible and safe in 
complex ACHD population undergoing radiofrequency ablation procedures.

\section{Abbreviations}

ACHD: Adults with complex congenital heart disease; EP: Electrophysiology; AA: Atrial arrhythmia; IART: Intra-atrial-re-entrant tachycardia; MAT: Macroreentry atrial tachycardia; AFL: Atrial flutter; HGMC: HD Grid mapping catheter; EGM: Electrograms; RA: Right atrium; AV: Atrioventricular; IVC: Inferior vena cava; SVC: Superior vena cava; CTI: Cavotricuspid isthmus; CL: Cycle length; ms: Milliseconds; PVI: Pulmonary vein isolation; d-TGA: Dextro-transposition of the great arteries.

\section{Acknowledgements}

Donald Knapik, MSc.Wendy Yeh, BA.

\section{Authors' contributions}

Both MP and SC analyzed and interpreted the patient data and prepared the manuscript. All authors read and approved the final manuscript.

\section{Funding}

None.

\section{Availability of data material}

All data generated or analysed during this study are included in this published article.

\section{Declarations}

\section{Ethics approval and consent to participate}

Not applicable.

\section{Consent for publication}

Written informed consents for publication of their clinical details and/or electrophysiological images were obtained from the patients. A copy of the consent form will be available for review by the Editor of the journal.

\section{Competing interests}

The authors declare that they have no competing interests.
Received: 24 March 2021 Accepted: 22 July 2021

Published online: 20 August 2021

\section{References}

1. Sherwin ED, Triedman JK, Walsh EP. Update on interventional electrophysiology in congenital heart disease: evolving solutions for complex hearts. Circ Arrhythm Electrophysiol. 2013;6(5):1032-40.

2. Morton JB, Sanders P, Vohra JK, Sparks PB, Morgan JG, Spence SJ, et al. Effect of chronic right atrial stretch on atrial electrical remodeling in patients with an atrial septal defect. Circulation. 2003;107(13):1775-82.

3. Walsh EP. Interventional electrophysiology in patients with congenital heart disease. Circulation. 2007;115(25):3224-34.

4. de Bakker JM. Electrogram recording and analyzing techniques to optimize selection of target sites for ablation of cardiac arrhythmias. Pacing Clin Electrophysiol. 2019;42(12):1503-16.

5. Ueda A, Suman-Horduna I, Mantziari L, Gujic M, Marchese P, Ho SY, et al. Contemporary outcomes of supraventricular tachycardia ablation in congenital heart disease: a single-center experience in 116 patients. Circ Arrhythm Electrophysiol. 2013;6(3):606-13.

6. Delacretaz E, Ganz LI, Soejima K, Friedman PL, Walsh EP, Triedman JK, et al. Multi atrial maco-re-entry circuits in adults with repaired congenital heart disease: entrainment mapping combined with three-dimensional electroanatomic mapping. J Am Coll Cardiol. 2001;37(6):1665-76.

7. Hong KL, Redfearn D, Chacko S, Baley J, Baranchuk A, Glover BM. Highresolution mapping of the atria using the HD Grid catheter. HeartRhythm Case Rep. 2019;5(7):351-3.

8. Okubo K, Frontera A, Bisceglia C, Paglino G, Radinovic A, Foppoli L, et al. Grid mapping catheter for ventricular tachycardia ablation. Circ Arrhythm Electrophysiol. 2019;12(9):e007500.

\section{Publisher's Note}

Springer Nature remains neutral with regard to jurisdictional claims in published maps and institutional affiliations.
Ready to submit your research? Choose BMC and benefit from:

- fast, convenient online submission

- thorough peer review by experienced researchers in your field

- rapid publication on acceptance

- support for research data, including large and complex data types

- gold Open Access which fosters wider collaboration and increased citations

- maximum visibility for your research: over $100 \mathrm{M}$ website views per year

At BMC, research is always in progress.

Learn more biomedcentral.com/submissions 